University of Nebraska - Lincoln

DigitalCommons@University of Nebraska - Lincoln

Mammalogy Papers: University of Nebraska

State Museum

Museum, University of Nebraska State

6-1-1984

Functional Cranial Analysis of Large Animalivorous Bats

(Microchiroptera)

Patricia W. Freeman

University of Nebraska-Lincoln, pfreeman1@unl.edu

Follow this and additional works at: https://digitalcommons.unl.edu/museummammalogy

Part of the Zoology Commons

Freeman, Patricia W., "Functional Cranial Analysis of Large Animalivorous Bats (Microchiroptera)" (1984). Mammalogy Papers: University of Nebraska State Museum. 7.

https://digitalcommons.unl.edu/museummammalogy/7

This Article is brought to you for free and open access by the Museum, University of Nebraska State at DigitalCommons@University of Nebraska - Lincoln. It has been accepted for inclusion in Mammalogy Papers: University of Nebraska State Museum by an authorized administrator of DigitalCommons@University of Nebraska Lincoln. 
Published in Biological Journal of the Linnean Society (1984), 21: 387-408. Copyright (C 1984

The Linnean Society of London. Published by Blackwell Publishing. Used by permission.

"The definitive version is available at www.blackwell-synergy.com ."

\title{
Functional cranial analysis of large animalivorous bats (Microchiroptera)
}

\author{
Patricia W. Freeman \\ Division of Zoology, University of Nebraska State Museum \\ Lincoln, Nebraska 68588-0514, U.S.A. \\ Accepted for publication 15 December 1982
}

\begin{abstract}
Large animalivorous bats include carnivorous, piscivorous and insectivorous microchiropterans. Skull proportions and tooth morphology are examined and interpreted functionally. Four wide- faced bats from four families are convergent in having wide skulls, large masseter muscle volumes and stout jaws, indicating a powerful bite. Three of the four also have long canine teeth relative to their maxillary toothrows. Carnivorous bats have more elongate skulls, larger brain volumes and larger pinnae. The wide-faced bats are all oral emitters and have heads positively tilted relative to the basicranial axis. The carnivorous species are nasalemitting bats and have negatively tilted heads. The orientation of the head relative to the basicranial axis affects several characters of the skull and jaws and is not correlated with size. The speculation that the type of echolocation may be more of a determinant of evolutionary change than the feeding mechanism is addressed. Wide-faced bats are thought to be capable of eating hard prey items (durophagus) and are probably non- discriminating, aurally less sophisticated insect generalists while the carnivorous and non-durophagus insectivorous bats may be more discriminating and aurally more sophisticated in what they eat.
\end{abstract}

KEY WORDS: Chiroptera, carnivory, insectivory, jaws, skull orientation, functional morphology, ear shape.

\section{CONTENTS}

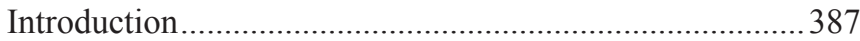

Materials and methods ..................................................... 388

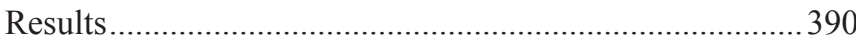

Discussion and functional implications ............................395

Conclusion …………....................................................401

Acknowledgements.............................................................403

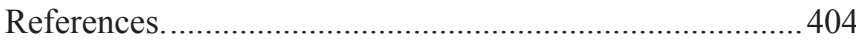

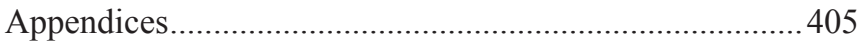

\section{INTRODUCTION}

The radiation of feeding specialties - insectivory, carnivory, piscivory, frugivory, nectarivory, and sanguivory - found among the microchiropteran bats offer an excellent opportunity to study changes in skull shape and tooth morphology in a monophyletic group. Here I focus on differences in the animalivorous bats, specifically among the insectivorous, piscivorous, and carnivorous, and on the possibility of inferring more specific food habits based on skull and tooth morphology. 
From earlier studies (Freeman, 1979, 1981) I wanted to know whether the prominent features characteristic in insectivorous bats thought to be eating hard items (durophagus bats) were accentuated in carnivorous bats. These features include stout jaws, large molars, long canines, and abbreviated upper third molars. Is beetle-eating, or durophagy, a stepping stone to carnivory or is carnivory something completely different? I had thought that chewing vertebrate bone and flesh would be physically harder, i.e. take more compressive force for a bat than chewing hard-shelled prey like beetles. But Curry (1970: 30) reported that vertebrate bone had a lower specific $E$ (modulus of elasticity or stress over strain ratio divided by specific gravity of the material) and took less compressive force to break than locust cuticle. Lucas (1979) mentions that uncalcified vertebrate tissue is soft under compression. Although Curry's data are somewhat counterintuitive, Goldman \& Henson (1977) have seen that eating certain beetles is impossible for some bats even though the bats are able to capture the beetle. The change in the nature of the food item from a hard-covered package with soft insides to a soft-covered package with hard insides must certainly be correlated with morphological changes in bats preying on these food items. The exact nature of insect cuticle as a nitrogenated polysaccaride and bone as a mineral, hydroxyapatite, is not examined here nor is the elasticity or tensile strength of the two materials. Curry (1970: 30) does report that the specific tensile strength is similar in the two materials but insect cuticle is less elastic. Different parts of the insect, for example the soft abdomen, would probably have different degrees of elasticity.

I cannot answer the question "why are there carnivorous bats?," but I can examine here cusp patterns and simple jaw, skull and ear proportions of these bats to find out what makes them different from insectivorous bats and how that difference may play a role in detecting and procuring prey.

Carnivory occurs in several families of microchiropterans, notably the Phyllostomidae and the Megadermatidae and, because most of the carnivorous bats are large, I thought it reasonable to compare them with the largest insectivorous species from other microchiropteran families. The largest examples of microchiropterans may also represent the ends of distinctly different paths of radiation (Stanley, 1973). Small-sized species from each family, except Noctilionidae, have been added for comparative purposes.

\section{MATERIALS AND METHODS}

I measured 23 characters of one adult male specimen for each of 33 species from seven families either with dial calipers under a dissecting microscope or with a protractor. The occlusal surface of the upper toothrow and the left lateral side of the skull were drawn under a camera lucida for each bat to facilitate measurement (Fig. 1). Tooth areas were determined with a polar planimeter from an enlarged drawing. Volumes and areas are always converted to the appropriate root for comparison with linear measurements. The basicranial axis can easily be observed by gluing an insect pin to the basicranium. The glue (Duco cement) sets quickly and is easily removed after use. An additional character, ear (pinna) area, was taken from as many as four adult wet specimens (usually two males and two females) found in the collection at the Field Museum of Natural History except for Macroderma gigas. Length of ear was taken at the notch and width taken at the widest point perpendicular to length. If the width of the ear had much curvature, the measurement was taken by folding the ear lengthwise and adding the two widths on either side of the fold. 
Ear area could not be obtained for four species. Bats designated as carnivorous, and for which a substantial amount of food habit data exists, are: Vampyrum spectrum, Phyllostomus hastatus, Chrotopterus auritus, Trachops cirrhosus, Macroderma gigas, Megaderma lyra, Cardioderma cor, and Nycteris grandis. Noctilio leporinus is piscivorous. Large insectivorous bats here are species with a greatest skull length generally longer than $25 \mathrm{~mm}$ and if not longer, they are the largest species of their families. All species and their abbreviations are listed in the Appendix along with descriptions of the measurements.

Simple bivariate plots were made for each character logged to base 10 (angles were not logged) against a composite size character, always the $x$ axis (SIZE $=$ sum of the natural logs of condylocanine length, zygomatic breadth, and temporal height). Reduced major axes were derived rather than regressions because, like Radinsky (1981a,b), I wanted to know the structural relationship of each variable with respect to SIZE rather than the

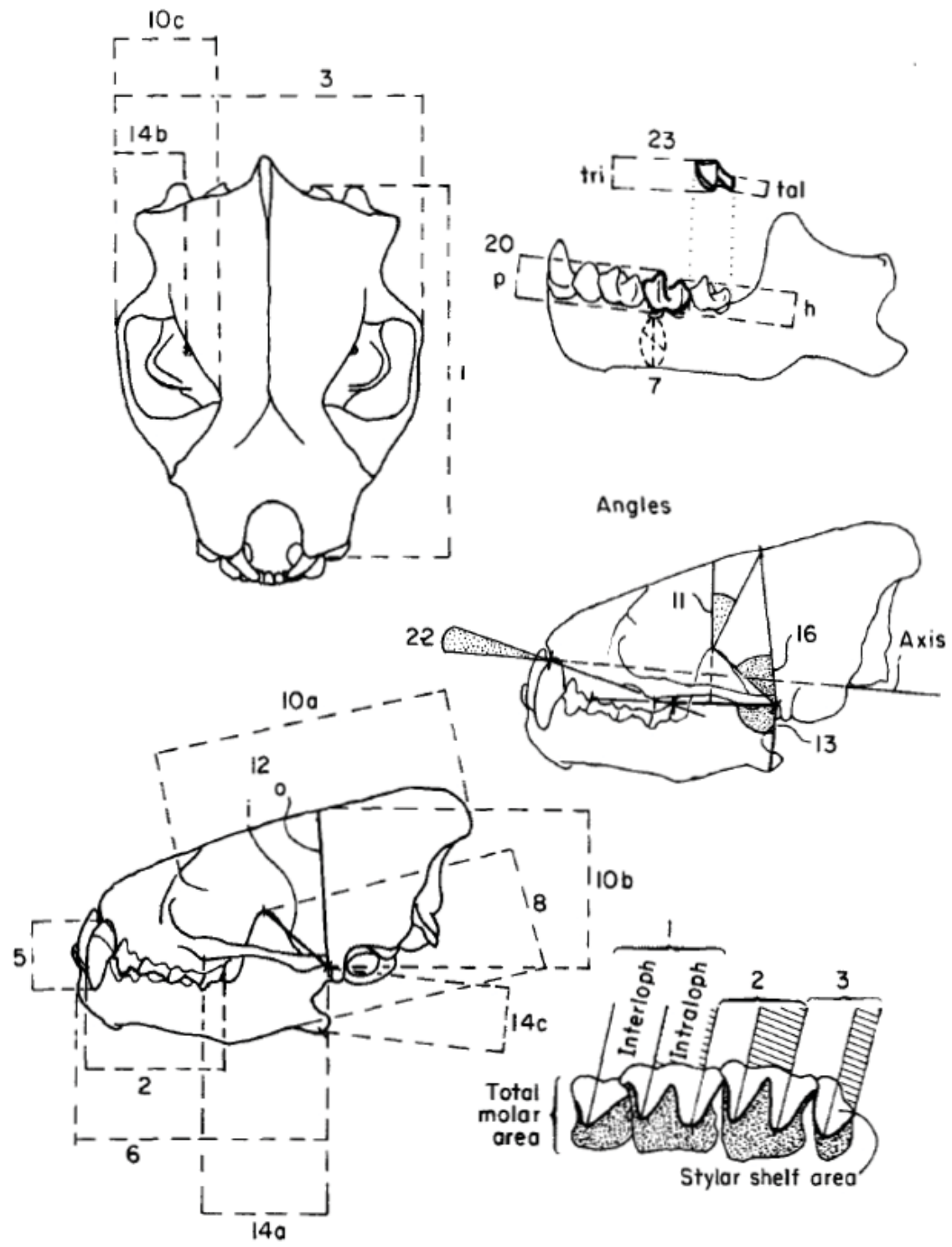

Figure 1. Dorsal and lateral views of a skull and mandible and an occlusal view of the upper molars illustrating most of the characters, including angles, used in the study. Numbers correspond to the descriptions listed in Appendix 2. 
effect SIZE might have on the variable. Further explanation for this method can be found in Clarke (1980). In the multivariate case, this would be the principal component analysis. Additionally, ratios of several measurements, indicating important shape relationships, are examined. Reduced major axes were also found for all characters $v$. basicranial angle. Means, standard deviations, correlations, slopes, and $y$ intercepts are listed in Appendix 4.

\section{RESULTS}

The most obvious adaptations for carnivory can be seen in the teeth. Carnivorous bats have a lengthened, more antero-posteriorly oriented, metastylar ridge on the upper molars (Figs 2, 3A; see also Slaughter, 1970). The lengthening of the metastylar ridge (metacrista) is accompanied by the enlarging of the reciprocal protoconid. The protoconid shears against the metacrista of the more anterior molar (or the parastyle of $\mathrm{P}^{4}$ ) and the paracrista of the following molar. This is a functional unit that I will call the interloph (ridge shared between teeth) and is followed by the ridge that the smaller hypoconid contacts, the intraloph (the internal ridge), a functional unit made up of the postparacrista and premetacrista (Fig. 1). In carnivorous bats, the intraloph is much smaller than the interloph so the ratio
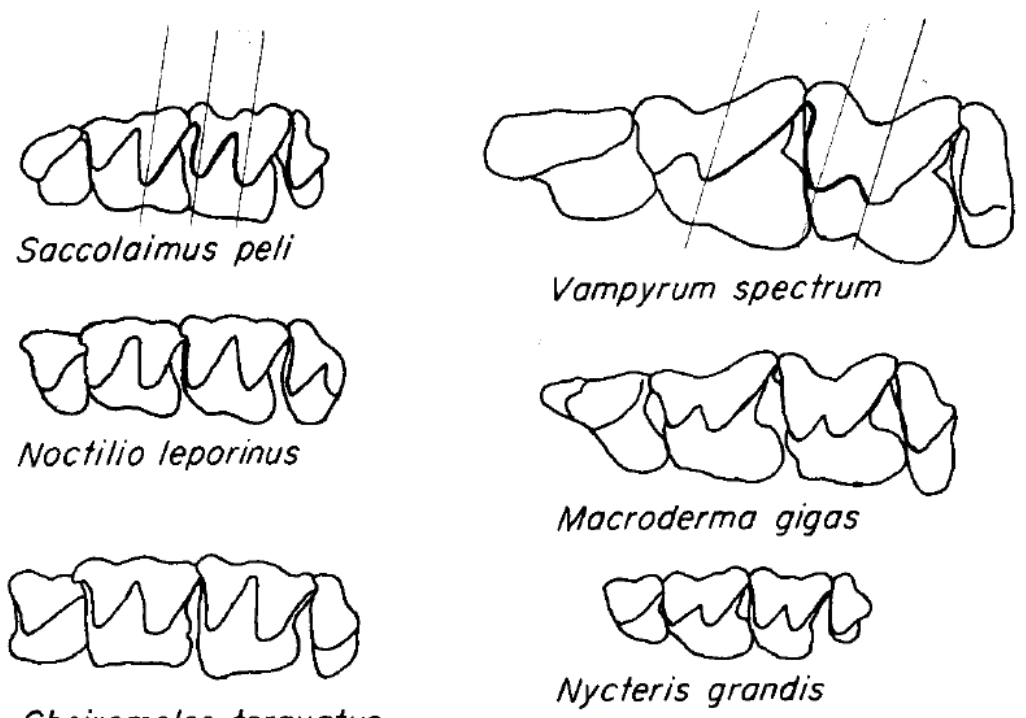

Cheiromeles torquatus
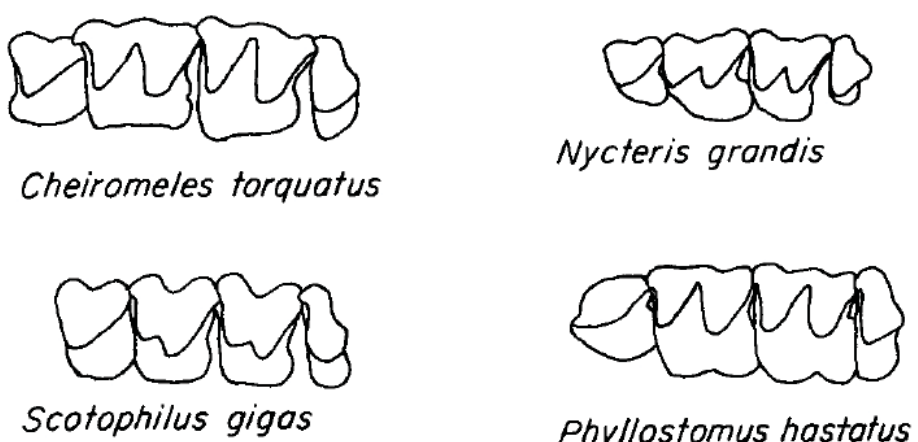

Phyllostomus hastatus

Figure 2. (above) Upper toothrows of the four wide-faced, insectivorous bats on the left and four carnivorous bats on the right. The intraloph (stipple) and interloph are shown for each group. All are drawn to the same scale.

Figure 3. (right) Important tooth characters of insectivorous and carnivorous bats. A. The four intraloph/interloph ratios for each bat, three molars and one total, correlated with SIZE; B. $\mathrm{M}_{2}$ Hypoconid/Protoconid ratios and $\mathrm{M}_{3}$ Talonid/Trigonid ratios (graphed together for convenience; diagrammatic cusps are drawn along the axes to show the change in relative sizes; $x$ axis shows occlusal views of $\mathrm{M}_{3}$ and $\mathrm{M}^{3}$, the $y$ axis the lateral view of $\mathrm{M}_{2}$ ); C. relative molar area correlated with SIZE; and D. relative stylar shelf area correlated with SIZE. Description of SIZE can be found in Materials and methods. Abbreviations are in Appendix 1. Carnivorous bats are denoted by $\mathrm{a}+$. Intraloph/interloph ratios: $-=\mathrm{P}^{4}-\mathrm{M}^{3} ; \mathrm{O}=\mathrm{P}^{4}-\mathrm{M}^{1} ; \bullet=\mathrm{M}^{1}-\mathrm{M}^{2} ; \star=\mathrm{M}^{2}-\mathrm{M}^{3}$. 

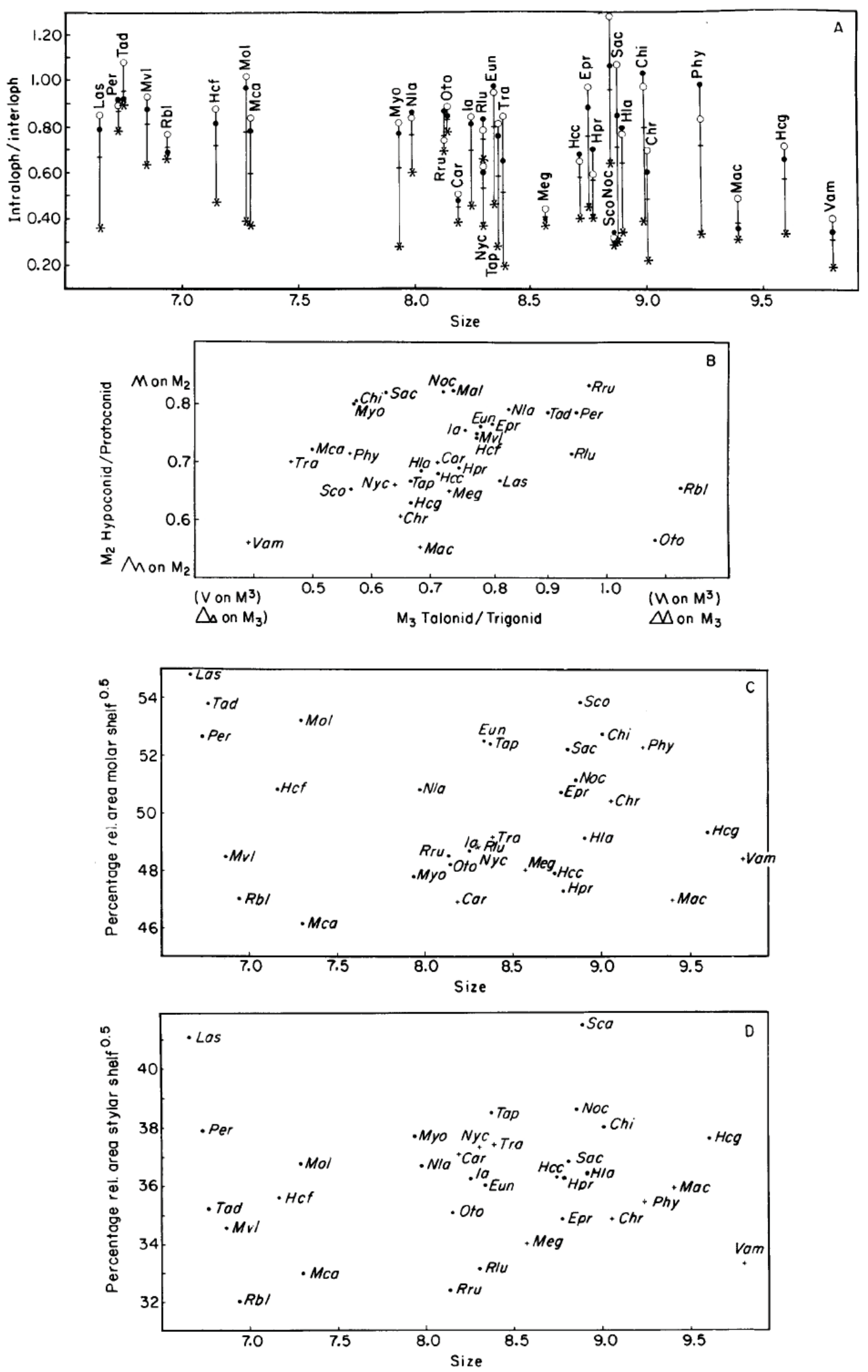
between the two is always less than 1.0. Insectivorous bats, on the other hand, have an intraloph and interloph that are subequal; the ratio between them approaches 1.0 (Figs 2, 3A) and the corresponding lower cusp, the hypoconid, is nearly the same size as the protoconid.

Change in the proportion of the heights of the reciprocal protoconid and hypoconid of $\mathrm{M}_{2}$ varies and can also be expressed as a ratio (Fig. 3B). The more equal the two lower cusps on $\mathrm{M}_{2}$, the closer the ratio is to 1.0. The ratio is less than 1.0 because of the larger protoconids and smaller hypoconids of the carnivorous bats.

The loss of the premetacrista of $\mathrm{M}^{3}$ (posteriormost cusp) and the corresponding reduction of the talonid in $\mathrm{M}_{3}$ has been mentioned in previous papers as a feature characteristic of bats that primarily eat hard-shelled insects (Freeman, 1979, 1981a). This feature can be represented by the talonid/trigonid ratio of $\mathrm{M}^{3}$ (Fig. 3B). All of the carnivores have a small ratio, meaning a small talonid relative to trigonid, and two, Vampyrum spectrum and Trachops cirrhosus, have the smallest ratio of all the bats in this study. Interestingly, Noctilio leporinus, a piscivorous bat, has retained the premetacrista of $\mathrm{M}^{3}$ (Fig. 2).

In a comparison of relative occlusal tooth areas, the carnivorous bats do not have as great an area of the upper molar row $\left(\mathrm{P}^{4}-\mathrm{M}^{3}\right)$ as many of the insectivorous bats. The insectivorous bats also have a relatively larger stylar shelf, the raised shelf labial to the ectoloph (Figs 3C, D) . The stylar shelf in the carnivores is more elevated relative to the hypoconal basin than in insectivores, but I had no way of measuring the difference.

Besides the changes in the teeth and cusps of carnivorous bats, the most striking difference among animalivorous bats is the shape of the skull. Four bats from four families, Noctilio leporinus, Cheiromeles torquatus, Scotophilus gigas and Saccolaimus peli, have converged toward having short, wide faces where the zygomatic breadth is $70-80 \%$ of the condylocanine length (Figs 4, 5). Both measurements, zygomatic width and condylocanine length, were compared to SIZE to see exactly which measurement affected this ratio. Of the four, Noctilio has an average zygomatic width but a disproportionately small condylocanine length. The other three had both wider zygomata for their size and short condylocanine lengths although not as short as Noctilio (Appendix 3 ). These four also have relatively wider distances across the maxilla at the $M_{3}$ s. The relatively wide faces of these four bats are in the same range as that of several felids and hyaenids. The carnivorous bats and the remaining insectivorous bats have narrower, more elongate faces (zygomatic breadth is $55-70 \%$ of condylocanine length) more like many of the canids (Fig. 5). As one may suspect, the width of the skull affects many proportions of the jaw and teeth. These four bats have relatively greater masseter muscle volumes and Noctilio and Scotophilus have relatively greater temporal muscle volumes as well (Figs 4B, C).

Although there is a tendency for relative canine length to increase with larger bats (the line in Fig. 4D is only just significant), three of the four bats mentioned above have canines that are $50-60 \%$ of maxillary toothrow length. The proportion is much like that in cats. In addition to Scotophilus, Cheiromeles, and Noctilio, Hipposideros commersoni commersoni and H. c. gigas have relatively long canines. The latter two have unusually well-developed sagittal crests and resulting temporal muscle volumes suggesting some specialized canine use (Fig. 6). It is not so much the absolute length of the canines that 

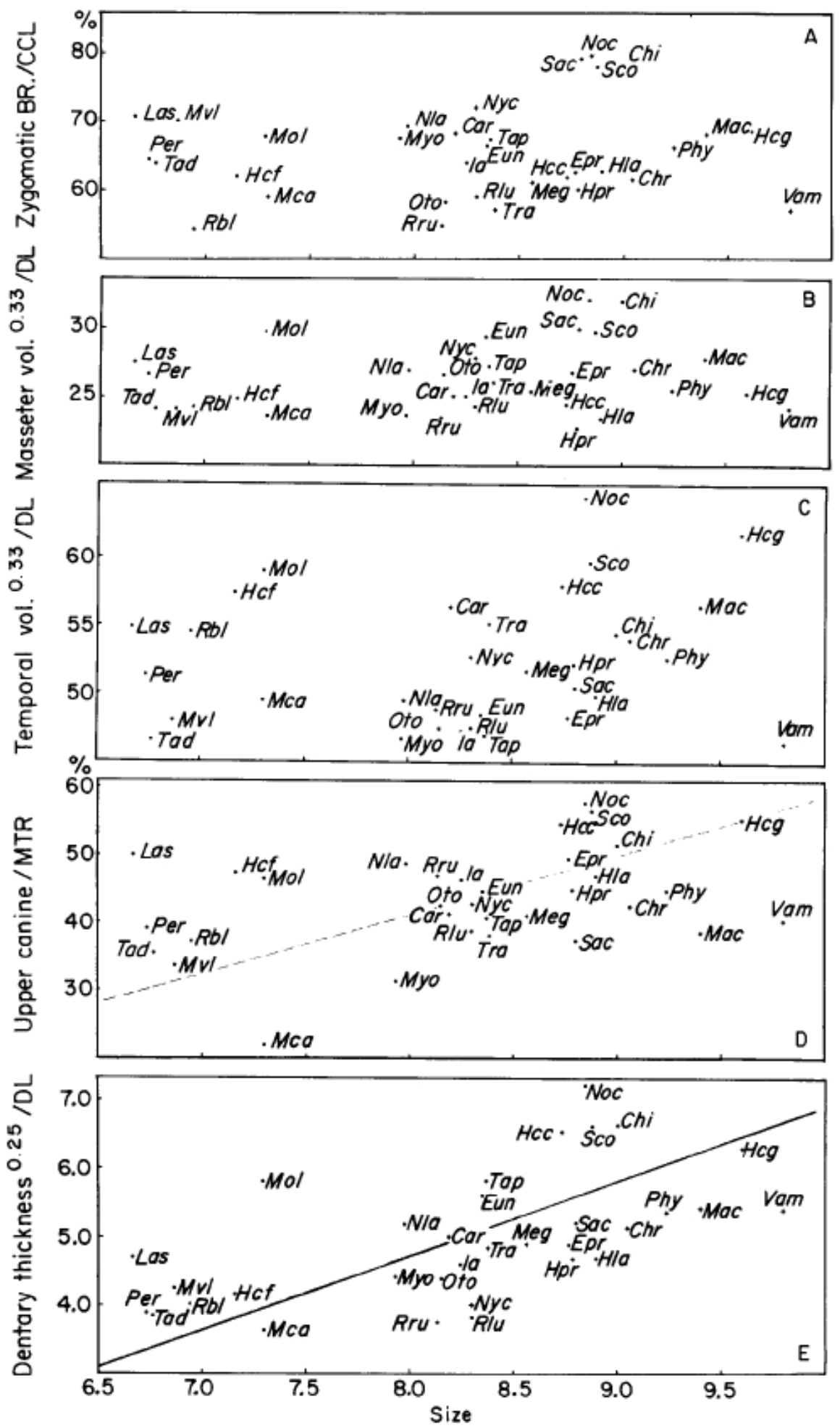

Figure 4. Important ratios describing changes in proportions of the skull in insectivorous and carnivorous bats: A, relative zygomatic breadth correlated with SIZE; B, relative masseter volume correlated with SIZE; C, relative temporal volume correlated with SIZE; D, relative upper canine length correlated with SIZE; E, relative dentary thickness correlated with SIZE. Carnivorous bats are designated by a + . Correlation coefficients are listed in Appendix 4 and abbreviations in Appendix 1. 
makes the ratio interesting as it is the short maxillary toothrow. When the toothrow is correlated with SIZE, Scotophilus, Noctilio, Cheiromeles and Hipposideros commersoni have among the shortest lengths (Appendix 3).

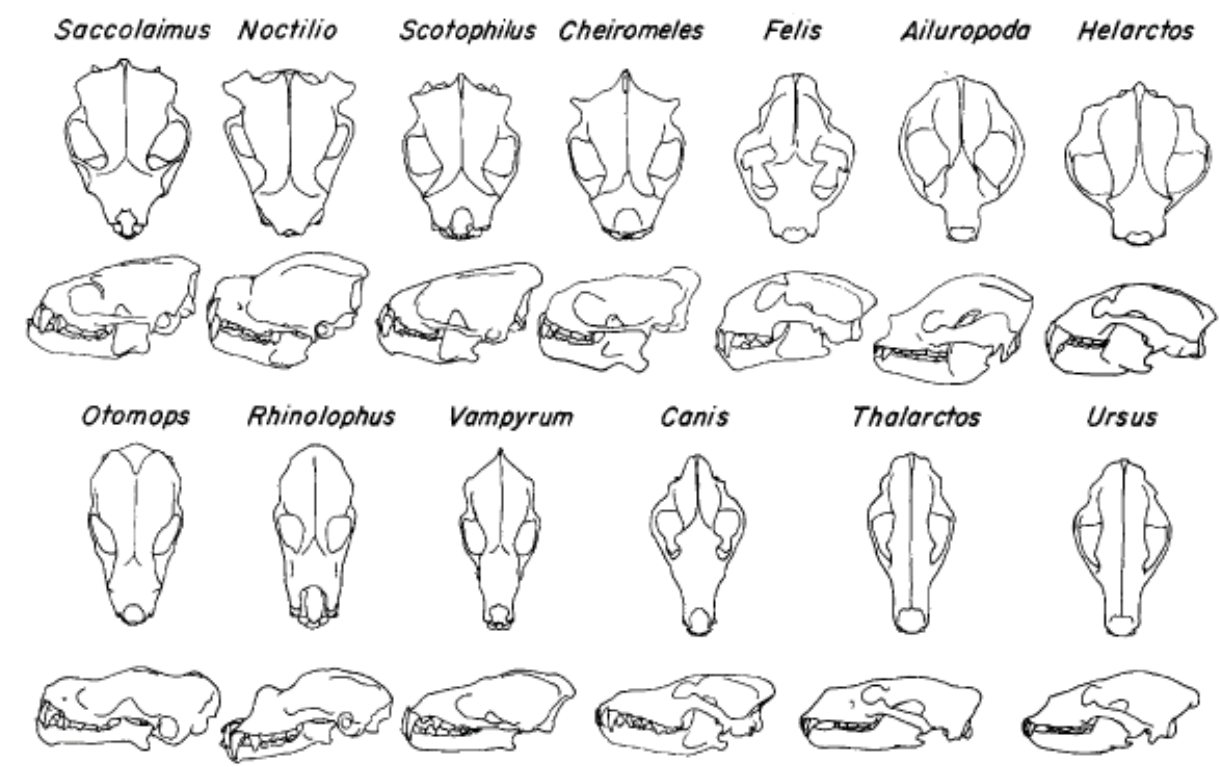

Figure 5. A comparison of wide-faced bats, felids, and ursids with bats with more elongate faces, canids, and ursids. All are drawn to approximately the same size.
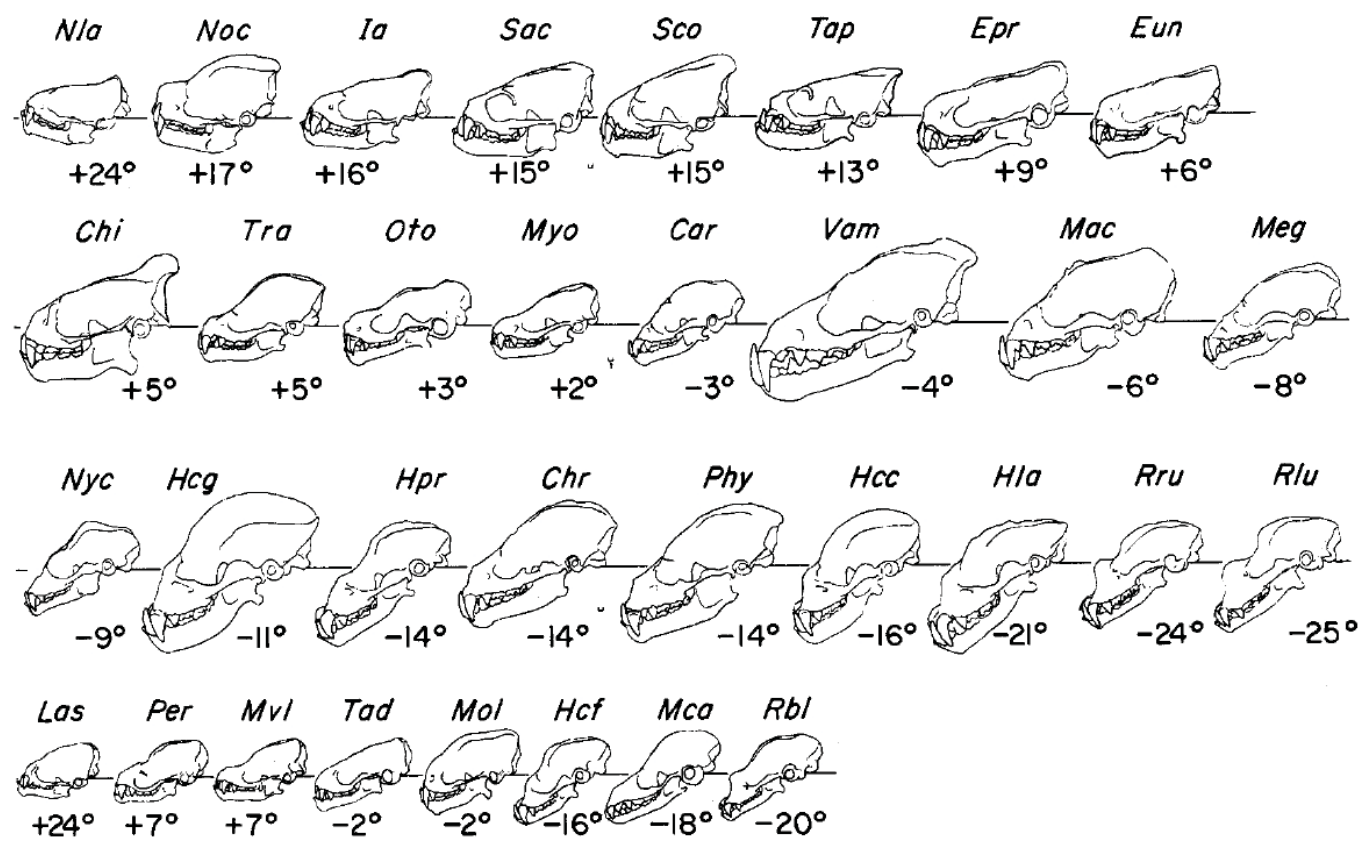

Figure 6. All the bats in the study arranged with the basicranial axis on the horizontal from the most positively tilted (Nyctalus lasiopterus at $+24^{\circ}$ ) to the most negatively tilted (Rhinolophus luctus at $-25^{\circ}$ ) plus the eight small-sized species. The scale is equal to $1 \mathrm{~mm}$. Abbreviations are in Appendix 1. 
The carnivorous bats tend to have thinner dentaries, lower condyles, and larger brain volumes than the wide-faced bats but not compared to the other insectivorous bats (Appendix 3). Dorso-ventral tilting of the head on the basicranial axis is negative for all the carnivores except Trachops. The wide-faced insectivores all have a positive tilt. A vector to the midpoint of the temporal muscle indicating the orientation of the temporal fossa in the carnivores seems indistinguishable from the insectivores.

\section{FUNCTIONAL IMPLICATIONS AND DISCUSSION}

The lengthening and more anterior-posterior orientation of the metastylar ridge on upper molars in mammals has long been associated with flesh eating because of its increased ability to slice material instead of crush it. Ewer (1973) discusses these traits in Recent Carnivora such as canids, and Osborn (1907) illustrates the change in the carnassial molars in Fissipedia and Creodonta. Carnivorous bats do not go as far as many of the carnivorans because they still retain metacones and hypoconids and have no single carnassial pair of teeth, features that may indicate they still have a healthy proportion of insects in their diet or that they have only recently adopted carnivorous habits. The cusp pattern change for increased slicing ability seen in these flying insectivores is distinctly different from that seen in terrestrial insectivorans such as the Tenrecids and Chrysoclorids, with zalambdodont teeth that Mills (1966) says are "specialized for pure cutting action".

The intraloph/interloph relationship, indicating metastylar change, for each of the upper molars is illustrated in Fig. 3A. Although the ratio for the third intra-interloph ratio $\left(\mathrm{M}^{2}-\mathrm{M}^{3}\right)$ is low for all the carnivores, only four of the carnivores have all three intra-interloph ratios of 0.51 or less: Vampyrum spectrum, Macroderma gigas, Megaderma lyra, and Cardioderma cor. Do these four have a greater proportion of flesh in their diets than the other carnivorous bats? Interestingly, the two closely-related phyllostomids, Vampyrum spectrum and Phyllostomus hastatus, both large bats, have distinctly different molar patterns (Fig. 2; Slaughter, 1970; Yalden \& Morris, 1975: 47). Phyllostomus hastatus is more catholic in its foods of fruit, insects, and flesh, than Vampyrum, a bird specialist (Gardner, 1977; Dunn, 1933; Vehrencamp, Stiles \& Bradbury, 1977). As can be seen in Fig. 3A, the ratios describing the first $\left(\mathrm{P}^{4}-\mathrm{M}^{1}\right)$ and second $\left(\mathrm{M}^{1}-\mathrm{M}^{2}\right)$ intra-interloph relationships of Phyllostomus are well into the range of the ratios found in insectivorous bats. Trachops, a phyllostomid that eats both insects and vertebrates, especially frogs (Gardner, 1977; Pine \& Anderson, 1979; Tuttle \& Ryan, 1981) and Chrotopterus, a larger phyllostomid that eats vertebrates, insects, and fruit (Gardner, 1977; Sazima, 1978), both have first and second intra-interloph ratios similar to many insectivores. The possible correlation between cusp shape and the proportion of vegetable, insect or vertebrate material in the diets of these phyllostomid carnivores has not been examined, but it would be interesting to compare the food habits of Chrotopterus and Phyllostomus hastatus, two similarly sized and closely-related bats.

If small intra-interloph ratios indicate an increased proportion of flesh in the diet, then Macroderma, Megaderma and Cardioderma ought to be strictly carnivorous. Macroderma, the largest Old World carnivorous bat, does have a large proportion of vertebrate material in its diet although it eats insects (Douglas, 1967). But Megaderma and Cardioderma both eat a considerable amount of insect material, especially during the season when insects are most abundant (Vaughan, 1976; Advani, 1981). Indeed, Vaughan found 
that Cardioderma in Kenya consumed large arthropods, both terrestrial and aerial, most of the year. Cardioderma and Nycteris grandis are the smallest carnivorous species in the study along with Trachops. Nycteris, once thought to be only insectivorous, eats vertebrate material as well (Whitaker \& Findley, 1980; Fenton, Thomas \& Sasseen, 1981). The cusp pattern for Nycteris could be interpreted to be insectivorous-carnivorous, but I would not have expected Cardioderma, with its sectional teeth to have as high a proportion of insect material in its food as this one study indicates. Of course, as a small 'carnivore,' it does take insect material of surprisingly large sizes (up to $80 \mathrm{~mm}$ ). Perhaps more food data for this bat will clarify why it has the cusp pattern that it has, but in general, there are no carnivorous bats in this study that do not have the small intra-interloph ratios. There does seem to be some slight correlation with increased amount of vertebrate material in the diet and size. Vampyrum and Macroderma feed almost exclusively on vertebrate material (Douglas, 1967; Vehrencamp, Stiles \& Bradbury, 1977).

The puzzling bat in Fig. 3A is Scotophilus gigas (possibly S. nigrita, Robbins, 1978). The pattern is that of a strict carnivore, but there are no good food data to support or refute this. Kingdon (1974) reports that he caught a specimen of $S$. nigrita with 2-3 g of beetles in its stomach, and Kock (1969) reported that this species would eat most types of insects in captivity and would attack and eat other bats put into the same cage. Kock (1969) also stated that $S$. gigas might be carnivorous and kill other bats, but his only evidence was the absence of other species in the same roost. Although the occlusal cusp pattern of $S$. gigas is that of a carnivore, the appearance of the teeth suggests more of a crushing than a slicing function. Indeed, the relative tooth areas of the upper molars and the stylar shelf area in this species are the greatest of any bat in the study. I suspect $S$. gigas to be insectivorous despite its cusp pattern for reasons discussed below.

Noctilio leporinus, a piscivore, has tooth characteristics more similar to the insectivores than to the carnivores. This may be a function of recent radiation from insectivory to piscivory. Its smaller congener N. labialis is primarily an insectivore. But it may also be that the characteristics of a piscivorous food item are similar to those of an insectivorous food item. An interesting feature of $N$. leporinus is that it has retained the posteriormost cusp on $\mathrm{M}^{3}$ (premetacrista), a feature different from the other wide-faced insectivorous bats with which it shares many characteristics. Could the retention of this cusp be related to piscivory? It does give the toothrow an additional cusp with which to hold slippery prey, and most fish-eating mammals have many small, pointed teeth by which to better grasp or hold their prey.

Carnivorous bats differ from insectivorous bats in having smaller tooth areas as measured in the occlusal plane. This is probably because of the increased slicing ability of the molars and less need of wide crushing surfaces. But the slicing edge, the ectoloph, especially at the metastylar ridge, is well-elevated above the hypoconal basin. This basin is low, expanded, and quite thin in the carnivores and looks as though it is becoming vestigial. Indeed, the lower this basin the deeper the ectoloph can cut through the soft muscular outer covering of the prey. Scotophilus with its carnivore-like cusp pattern has a rather well-developed hypoconal shelf with little expansion of the hypoconal basin (Fig. 2).

Phyllostomus hastatus, an omnivore, and Noctilio leporinus, a piscivore, do have greater relative molar areas, but the stylar shelf in P. hastatus is not great (Fig. 3D). The hypoconal basin is not expanded and thin in either of these two bats. Noctilio along with 
three insectivorous bats, Cheiromeles torquatus, Scotophilus gigas, and Saccolaimus peli, all have large molar areas and wide faces.

Of the four species that have wide faces (zygomatic breadth/condylocanine $=78-80 \%$ ), three of them, Noctilio, Cheiromeles, and Scotophilus gigas have long canines relative to their maxillary toothrow (greater than 50\%). Only Saccolaimus peli does not.

These two features, wide faces and long canines, taken together can be interpreted to mean that the bite is more powerful and effective. Because the long canines are closer to the fulcrum of the jaw lever and because the wide zygomatic arches allow for greater masseter muscle volume (Fig. 4B), these bats should have a strong, deeply piercing bite. Food data for these particular bats are slight, but I suspect they are capable of eating hard items. In an earlier study, I found that bats with a large portion of beetles in their diets did have relatively longer canines (Freeman, 1981a). Beetle remains have been found in both Cheiromeles and Scotophilus (Kock, 1969; Freeman, 1981b) . Noctilio leporinus has the longest canines and widest face, relatively, of all the bats examined. Spearing slippery vertebrate prey may need the same long canines as piercing hard insects (fish may also be hard).

Two additional bats with long canines are Hipposideros commersoni commersoni and H. c. gigas. Food habit data have shown that this species is a specialist of large, wellarmored beetles (Whitaker \& Black, 1976; Vaughan, 1977). The striking feature of the skull of this species is its unusually well-developed sagittal crest and resulting temporal muscle (Figs 4C, 6). In corroboration with potentially heavy and effective canine use are the structurally thick dentaries of $H$. commersoni, Cheiromeles, Scotophilus, and Noctilio (Fig. 4E, Appendix 3).

The height of the condyle above the toothrow tends to be greater in bats with wide faces (especially, relatively). According to Maynard Smith \& Savage (1959), this greater height allows for a longer moment arm and greater attachment area for the masseter and pterygoid muscles. Indeed Storch (1968) weighed the muscles in several species of bats with different food habits and found that the pterygoid muscles of Noctilio weighed $35 \%$ more than the masseter muscle. The zygomaticomandibularis and the pterygoids both are primarily involved with transverse movement of the jaw. I suspect that the development of transverse movement is especially important in all of the wide-faced bats. Mills (1967), in a paper comparing the lateral jaw movements of insectivorans points out that the different shapes of the zygoma and its relationship with the base of the skull (posterior attachment of the jugals?) and the coronoid processes could all three be indicative of the type of lateral movement of the lower jaw. The insectivoran with the wider zygoma (Erinaceus) was thought to have "quite marked lateral jaw movement". Although the insertion of the pterygoids on the inferior medial side of the dentary was not measured, the area for insertion in the wide-faced bats is large, particularly in Cheiromeles. All of these bats except Noctilio have high coronoid processes (Appendix 3).

One other characteristic that is indicative of muscle relationship, in this case the direction of the pull of the temporal, is the angle between the midpoint of that muscle and a perpendicular through the coronoid process (lateral view of skull, Fig. 1). The midpoint for Noctilio is only 7" left of centre and Lasiurus only $10^{\circ}$, indicating that the temporal fossa is more vertically oriented. The pull of the temporal for these two bats is nearly directly upward, almost perpendicular to the toothrow, whereas in Rhinolophus luctus and 
Nycteris grandis with angles of $57^{\circ}$ and $55^{\circ}$, respectively, the pull of the temporal is more backward. The midpoints of the two large carnivores Macroderma gigas and Vampyrum spectrum are from $36-37^{\circ}$ left of centre. The other wide-faced bats have angles from 26 $39^{\circ}$. Emerson \& Radinsky (1980) found that as the temporal fossa became more vertically oriented in sabertooth cats, the coronoid process was lower. This is the case with Noctilio. The change in the temporal to a more vertical position could mean a more efficient bite force for the temporal as Emerson \& Radinsky (1980) suggest, but this muscle orientation is also affected by the tilting of the head on the basicranial axis.

Reorienting the skulls in this small sample of bats from seven families so that the basicranial axis is horizontal reveals enormous differences (Fig. 6). Heads with positive angles of inclination generally belong to bats that emit their echolocating pulses orally and negative angles belong to nasal emitters. The range of difference is from $+24^{\circ}$ in Lasiurus borealis and Nyctalus lasiopterus to $-25^{\circ}$ in Rhinolophus luctus. Notice that the reorientation of Rhinolophus skulls cause the swollen nasal region to point directly forward. All four of the wide-faced bats have positive angles and are oral emitters. Trachops, a nasal emitting carnivore, is exceptional with a positive angle of $+5^{\circ}$, and Tadarida brasiliensis and Molossus molossus, both small oral emitters, have a slight negative angle of $-2^{\circ}$. For comparison, a single non-echolocating pteropid, Epomorphorus minor, was found to have an angle of $-9^{\circ}$.

Correlating all characters against the basicranial angle (BCA) reveals that the method of echolocating may be affecting several of the skull characters measured (Fig. 7). Height of the condyle above the toothrow has a strong positive correlation with BCA. High condyles occur only in the oral-emitting bats. Vertical orientation of the temporal fossa is negatively correlated with BCA such that the oral emitters have the more vertically oriented temporal muscle. Neither of these characters can be clearly interpreted at this time, but both must have to do with not only how prey is detected, but also how it is consumed.

A final interesting correlation is the relationship of external ear area and BCA. These are also negatively correlated so that the bats with the greatest area are the nasal emitters (negative BCA) and bats with the smallest are oral emitters (positive $\mathrm{BCA}$ ). The carnivores have the greatest ear areas as well as the greatest brain volumes (Fig. 7, Appendix 3).

The four wide-faced bats have small ears that are widely separated on the skull and appear to face a more lateral than anterior direction. I suspect that none of these bats have the ability to detect prey well in dense clutter (Simmons, Fenton \& O'Farrell, 1979, discuss kinds of calls in different habitats), but pursue prey in habitats with few or no obstacles. The ability to detect whether a target is coming or going is shown in the constant frequency (CF) component of the echolocating call (Simmons et al., 1979). Although three of these wide-faced bats have not been recorded in the field, their confamilials have a large CF component in their calls (Fenton \& Bell, 1981). Data suggest that although Noctilio has the ability to use multiple harmonic signals, which are usually associated with dense clutter, it routinely uses a single harmonic that may be best for detection of ripples or disturbance and the water surface (Simmons et al., 1979). Simmons (pers. comm.) suggests that Cheiromeles with its small widely-separated, laterally-facing ears may be hearing audible sounds of insects while avoiding obstacles with higher frequency sounds. 
Whatever the specifics of these wide-faced bats, it presently looks as though they may be better at target detection rather than for target identification and localization.

All of the carnivorous bats have large ear areas, large brain volumes, and well-developed nose leaves. Megaderma and Phyllostomus hastatus are known to have a "high reso-
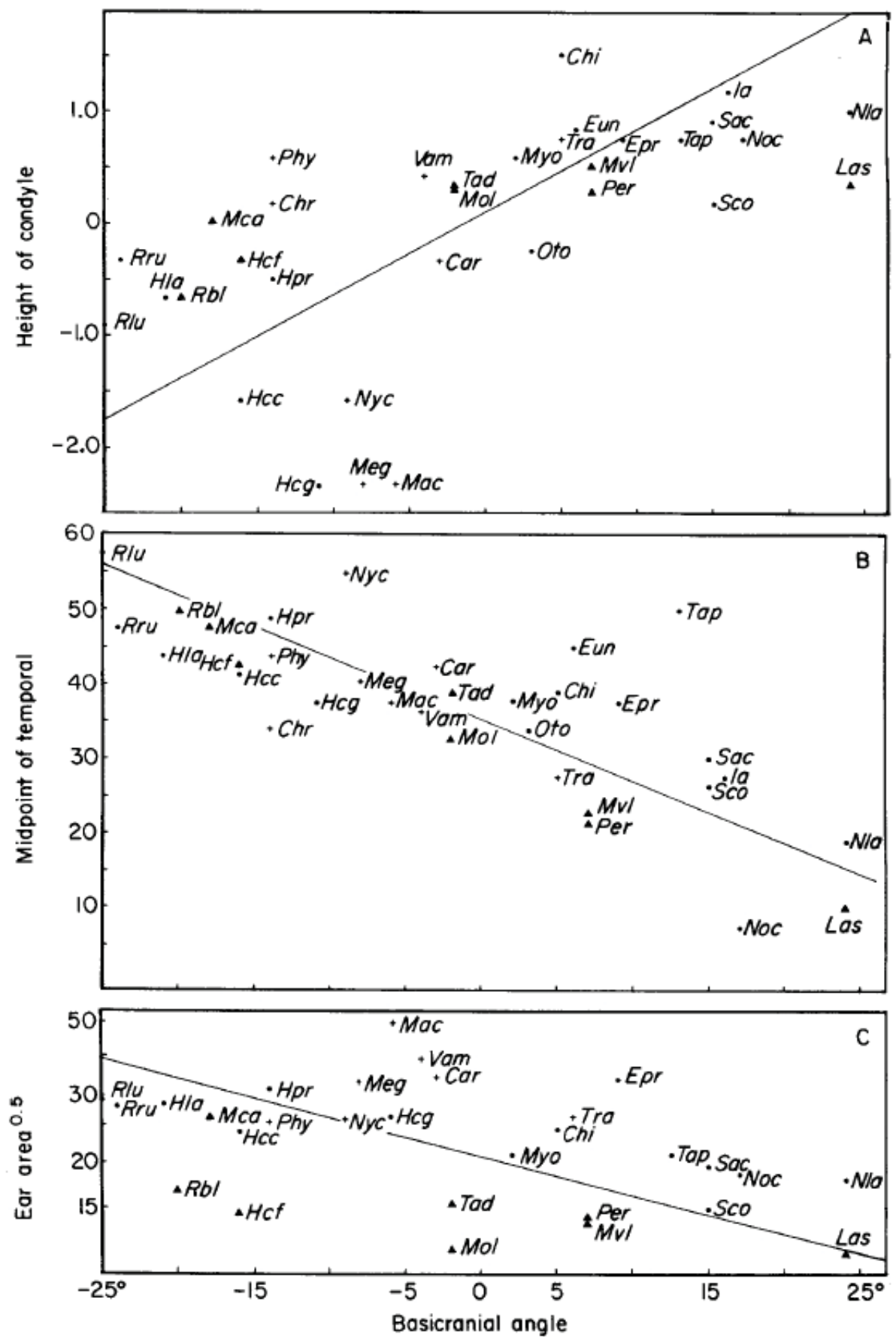

Figure 7. These three characters are significantly correlated with the basicranial axis (Appendix 4 has correlation coefficients). A. Height of condyle above the toothrow, B. midpoint of temporal fossa, C. ear area. In C, $S C O$ is represented by S. nigrita, Nla by N. noctula, and Chr, Eun and Oto are not represented. Carnivorous species are denoted with a + , small species by $\boldsymbol{\Delta}$, and abbreviations are in Appendix 1. 
lution, clutter-rejecting pursuit strategy" (Simmons et al.,1979). These are calls with multiple frequency modulated harmonics that are more sophisticated at determining what the object is rather than just its movement. Those bats as well as Cardioderma, Vampyrum, Nycteris grandis and Trachops all hear low intensity sounds well (Simmons \& Stein, 1980; Barclay et al., 1981). In addition, these bats perch on branches upside down scanning the environment with their heads cocked back, their ears and nose leaves constantly moving (Hipposideros commersoni also does this). These bats are also consuming prey while perching, whereas many of the aerial pursuers are probably both detecting and consuming prey on the wing.

Another way in which skull shape may be determined by auditory requirements in bats is suggested by the work of Masterton et al. (1969) and Heffner \& Heffner (1980) who think that it is the functional interaural distance that limits high frequency hearing in mammals. Test animals for these studies range from small to very large mammals; only three bats were included. The smallest (Myotis) had a high frequency cut-off greater than Eptesicus, then Rhinolophus. In a study of bats only, it would be interesting to see if bats with wide faces and widely separated ears heard high frequencies less well than bats of the same size, but with closer-set ears.

In all of the above discussion, nothing has been said about the gape of the jaws. Calculating gape in these bats is difficult and seems to involve several features peculiar to bats. First, what effect might the method of echolocating (oral or nasal emission) have on gape; and second, what effect might feeding while flying have on gape.

Several morphological characters may be related to how wide a bat could open its jaws. Herring \& Herring (1974) have investigated aspects of the superficial masseter on gape and Emerson \& Radinsky (1980) have looked at aspects of the temporal on gape in sabertooth cats. None of the animals examined echolocate or feed in the air. Bats tend to have a masseter origin/insertion ratio of greater than 1.0 and angle $\varphi$ of less than $90^{\circ}$. These features make the bats similar to Didelphis which has a wide gape (Herring \& Herring, 1974). Interestingly, Noctilio has a temporal origin/insertion ratio of 2.9 that is similar to sabertooths but its temporal $\varphi$ is only $62^{\circ}$. The remaining bats have an average temporal $\varphi$ of $67^{\circ}$ with a range $48^{\circ}$ to $94^{\circ}$, and temporal origin/insertion ratio average of 1.8 with a range of 1.3 (Eumops perotis) to 2.4 (Lasiurus borealis).

The use of a wide gape as a threat posture is common in molossids such as Nyctinomops macrotis, Eumops perotis, and Otomops martiennseni. The last two can open their mouths $90^{\circ}$ or more (Fig. 8; Howell, 1920; Walker, 1975), and Kallen \& Gans (1972) report the gape of Myotis lucifugus to be over $90^{\circ}$. These are all orally-emitting bats. None of the formulae estimating gape by Herring \& Herring, and used by Emerson \& Radinsky on sabertooths, predicted these wide gapes. Eumops perotis and Otomops martiennseni have long dentary lengths that would span a greater arc as the dentary is depressed and low coronoid processes that indicate longer temporalis fibres and greater stretch (Matthew, 19 10; Emerson \& Radinsky, 1980). Both are probably features of a greater gape. But other questions come to mind. If the basicranial angle is negative as in the nasal emitters, can the mouth open as widely or will the dentary be obstructed by the chest and neck? Does a laterally-flared angular process of the lower jaw allow greater depression of the dentary without being blocked by the neck muscles? Emerson \& Radinsky (1980) found that sabertooth cats, which were thought to have greater gapes than modern cats, 
had laterally displaced angular processes, low coronoids and vertically-oriented temporal fossae, and positive facial inclination relative to the basicranial axis (Eusmilus is the extreme with $+22^{\circ}$ ). These authors mention that with these features, and a lowered glenoid fossa, the mandible "would have impinged less on the structures ventral to the braincase or neck than in modern felids". Following this logic, Noctilio leporinus, which has laterally-flaring angular processes, with its low coronoids, vertically-oriented temporal fossa, and $+17^{\circ} \mathrm{BCA}$, should have a wide gape. Indeed, its high temporal origin/insertion ratio also in the range of the sabertooths, suggests wide gape. Is it coincidence that Noctilio has the longest upper canines relative to its maxillary toothrow among all large bats studied? Could Noctilio be considered a sabertooth bat?
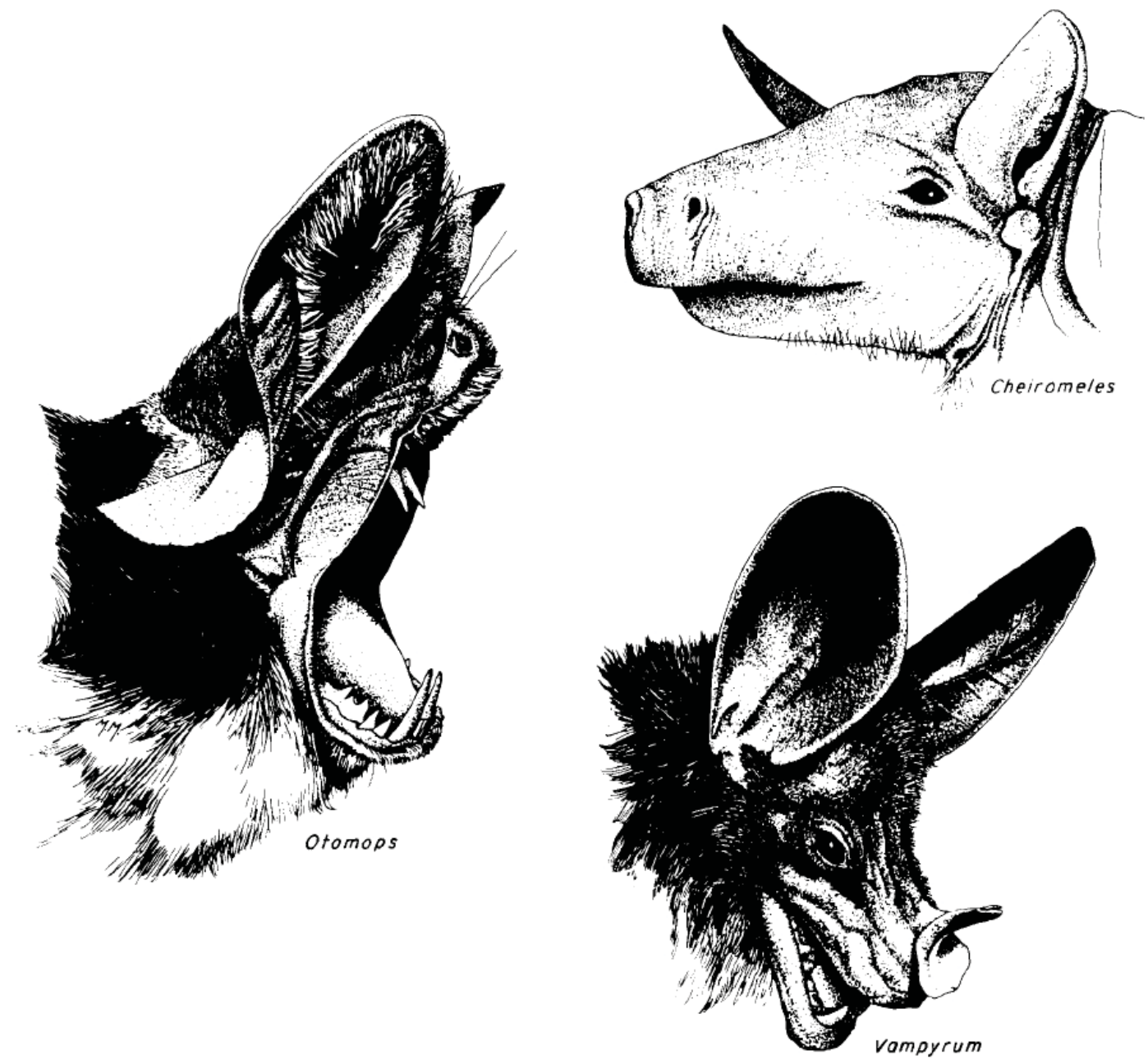

Figure 8. The faces of three bats: Otomops, an insectivore: Vampyrum, a carnivore; and Cheiromeles, a widefaced insectivore. 


\section{CONCLUSION}

Because all of these large animalivorous bats use their canines and temporal muscles to help in capture of prey items, whether soft or hard, analogy with members of Carnivora would not be out of order. Turnbull (1970) found much similarity in the musculature and lever mechanics with members of his Specialized Group I (the "carnivore-shear" or "scissors" type of mastication) and members of the Generalized Group that included insectivores. He did, however, point out that there was a lessening of importance of the pterygoideus musculature with the increase in the masseter group that offset the powerful temporalis, the primary prey-seizing muscle.

Several lines of Carnivora have increasingly wider skulls (Radinsky, 1981a,b), particularly mustelids and ursids. Sicher (1944) and Moore (1981) present this example: a polar bear, Thalarctos, with a narrow skull is strictly carnivorous; Ursus, a bear with intermediate skull width, is omnivorous; and Ailuropoda, the panda, has a wide skull and is strictly herbivorous (Fig. 5). This is a trend toward increased hardness of food. Davis (1964), too, gives an example of increasing power in carnivoran jaws with increasingly hard food. He calculated zygomatic breadth/condylobasal length ratios for three groups of carnivorans. The "generalized flesh-eating carnivores" like Canis and Viverra have a ratio of $57 \%$ and 50\%, respectively, the "predominantly herbivorous carnivores" like Procyon and Ailurus have a ratio of $68 \%$ and $75 \%$, respectively, and the "extremely powerful jawed carnivores" like Ursus, Hyaena, and Ailuropoda, have ratios of 63\%, 71\%, and 82\%, respectively. In Radinsky's study, Tayra has a ratio of $62 \%$ and Enkydra of $82 \%$; Thalarctos at 57\% and Helarctos at 93\%. This last has the widest skull of any bear, even greater than Ailuropoda, a specialist on hard bamboo. Radinsky (1981b) questions whether the wider skull in Helarctos does indicate that the jaws are more powerful and food items harder. He considered Helarctos an omnivore based on information from Walker (1975). Helarctos may not have specialized food habits like the panda, but it does have an unusual lifestyle. It is the only arboreal bear. Schaller (1964:216) reported that it makes nests out of sticks high in the trees. The bear weighs $65-80 \mathrm{~kg}$, about the size of an American black bear, and its limbs are modified for climbing. Perhaps the unusually wide jaws have a specific role in this arboreal lifestyle.

Widening of the skull is a frequent phenomenon in carnivorans, and, as is apparent in this study, in microchiropterans as well. Indeed, a recent study by Corruccini \& Beecher (1982) show that squirrel monkeys raised on hard food items have significantly wider dental arches (width of maxilla) than squirrel monkeys raised on soft foods. As in the example of the bears, I think the wide- faced bats have more powerful jaws than the insectivorous and carnivorous bats with more elongate faces and have the ability to chew very hard food items. Although the temporalis musculature still has the primary task of capturing prey items, probably the relative importance of the pterygoid and zygomaticomandibularis muscles, with their ability to move the jaw transversely, has increased. Exactly why increased transverse action might be an aid to mastication of hard insects has not yet been elucidated, but, certainly having less transverse activity in the carnivorous bats would mean having greater vertical movement and slicing ability.

An interesting trend in jaw and ear morphology can be seen in the molossids. Otomops and Cheiromeles are opposites in that the first has a low condyle and the second 
an elevated one. Both are oral emitters, but Otomops has enormous ears compared to the small laterally-facing ears of Cheiromeles (Fig. 8). Using the standard argument of Maynard Smith \& Savage (1959), the low condyle could mean that Otomops has a stronger temporal relative to its masseter and Cheiromeles has a stronger masseter relative to its temporal. In a previous paper I suggested that Otomops may be a soft-item insectivore and Cheiromeles, a hard- item insectivore, or at least that it could eat anything up to the hardness of beetles (Freeman, 1979). Otomops shares these two traits, large ears and low condyles, among others, with carnivorous bats. Perhaps the flesheating bats passed through an insectivore stage more similar to Otomops before becoming carnivores rather than a hard-item insectivore stage like Cheiromeles (see also Gillette, 1975).

Carnivorous bats with their elongate skulls have several features that are indistinguishable from insectivorous bats that I would consider soft-item specialists (Freeman, 1979). The flesh-eating bats are often bigger versions of the soft-item specialists. There are no very small strict carnivores in this study. Trachops cirrhosus, Nycteris grandis, and Cardioderma are known to eat insects as well as flesh. Also, because there are many characters in common among flesh- eaters and soft-item eaters, there is no distinct boundary where insectivory ends and carnivory begins. They both have elongate faces, thinner dentaries, lower condyles, larger brain cases, and bigger ear areas than their wide-faced relatives. Their bigger, closer-set ears may allow them to be more discriminating and aurally more sophisticated predators.

It is the wide-faced bats, durophagus bats, that are the unusual ones, and not the carnivorous bats. Because of their wide, powerful, jaws; long canines; large molars; robust jaws; and small, well-separated, laterally-facing ears, these bats may be non-discriminating and aurally less sophisticated generalists that can only target their prey and feed on any kind of edible insect, hard or soft. In addition, the powerful bite and long canines of the durophagus bats would be critical to the immediate puncturing of hard-shelled, possibly hardto-grasp prey while flying. On the other hand, the carnivorous bats could easily puncture their vertebrate prey but may need time to process it. The former may be eating on the wing while the latter are probably resting on a perch to eat.

Finally, there are several skull and jaw characters that are not correlated with size but are correlated with how the bat's head is held during life and potentially with its echolocating abilities. This suggests that echolocation and how the environment and prey are detected are a more important aspect of their biology than how prey are consumed. The tooth cusp pattern is still the primitive tribosphenic insectivorous pattern that has changed little in 65 million years while ears and noses have become very elaborate. Detecting morphological change that may be controlled by behavioral phenomenon such as echolocation rather than by the feeding mechanism in the skulls of these bats could have profound effects on microchiropteran taxonomy and phylogeny. Simmons \& Stein (1980) have already started looking at the evolution of bats in this light, and although I do not agree with their interpretation of what is primitive and derived (it is hard for me to believe that the carnivorous bats with elaborate ears and noseleaves and sophisticated ultrasonic calls are primitive), I commend them for their fresh approach and emphasis on this critical behavioral feature of microchiropterans. 


\section{ACKNOWLEDGEMENTS}

I thank curators at Field Museum of Natural History, American Museum of Natural History, United States National Museum, and the Royal Ontario Museum for their kindness in loaning me the necessary specimens. Field Museum supported early stages of this project. My colleague and spouse, Cliff Lemen, provided statistical help and curiosity about these big bats; both were important to my finishing the study. Mark Marcuson drew the figure of the three bat faces and helped with much of the art work and Gail Littrell typed several drafts without complaint. I thank Robert Hunt, Michael Voorhies, and Cliff Lemen for critically reading the final draft, and John H. Calaby of the CSIRO in Australia for sending me a wet specimen of Macroderma gigas in the nick of time.

\section{REFERENCES}

ADVANI, R., 1981. Seasonal fluctuations in the feeding ecology of the Indian false vampire, Megaderma lyra lyra (Chiroptera: Megadermatidae) in Rajasthan. zeitschrift fur Saugetierkunde, 46: 90-93.

BARCLAY, R.M.R., FENTON, M. B., TUTTLE, M. D. \& RYAN, M. J., 1981. Echolocation calls produced by Trachops cirrhosus (Chiroptera: Phyllostomatidae) while hunting for frogs. Canadian Journal of zoology, 59: 750-753.

CLARKE, M. R. B., 1980. The reduced major axis of a bivariate sample. Biometrika, 67: 441-446.

CORRUCCINI, R. S. \& BEECHER, R. M., 1982. Occlusal variation related to soft diet in a non-human primate. Science, 218: 74-76.

CURRY, J. D., 1970. Animal Skeletons. London: Edward Arnold.

DAVIS, D. D., 1964. The Giant Panda. A morphological study of evolutionary mechanisms. Field Museum of Natural History Fieldiana: Zoology Memoirs, 3: 1-339.

DOUGLAS, A. M., 1967. The natural history of the ghost bat, Macroderma gigas (Microchiroptera, Megadermatidae), in western Australia. The Western Australian Naturalist, 10: 125-138.

DUNN, L. H., 1933. Observations on the carnivorous habits of the spear-nosed bat, Phyllostomus hastatus panamensis Allen, in Panama. Journal of Mammalogy, 14: 188-199.

EMERSON, S. B. \& RADINSKY, L., 1980. Functional analysis of sabertooth cranial morphology. Paleobiology, 6: 295-312.

EWER, R. F., 1973. The Carnivores. Ithaca: Cornell University Press.

FENTON, M. B. \& BELL, G. P., 1981. Recognition of species of insectivorous bats by their echolocation calls. Journal of Mammalogy, 62: 233-243.

FENTON, M. B., THOMAS, D. W. \& SASSEEN, R., 1981. Nycteris grandis (Nycteridae) an African carnivorous bat. Journal of zoology, London, 194: 461-465.

FREEMAN, P. W., 1979. Specialized insectivory: Beetle-eating and moth-eating molossid bats. Journal of Mammalogy, 60: 467-479.

FREEMAN, P. W., 1981a. Correspondence of food habits and morphology in insectivorous bats. Journal of Mammalogy, 62: $166-173$.

FREEMAN, P. W., 1981b. A multivariate study of the family Molossidae (Mammalia, Chiroptera): Morphology, ecology, evolution. Field Museum of Natural History Fieldiana: zoology, n.s. 7: 1-173.

GARDNER, A. L., 1977. Feeding habits. In R. J. Baker, J. K. Jones, Jr., and D. C. Carter (Eds), Biology of bats of the New World family Phyllostomatidae. Part 11. Special Publications, The Museum, Texas Tech University, 13: 293-350.

GILLETTE, D. D., 1975. Evolution of feeding strategies in bats. Tebiwa, 18: 39-48.

GOLDMAN, L. J. \& HENSON, O. W., JR., 1977. Prey recognition and selection by the constant frequency bat, Pteronotus p. parnellii. Behavioral Ecology and Sociobiology, 2: 411-419.

HEFFNER, R. \& HEFFNER, H., 1980. Hearing in the elephant (Elephas maximus). Science, 208: 518-520.

HERRING, S. W. \& HERRING, S. E., 1974. The superficial masseter and gape in mammals. The American Naturalist, 108: 561-577.

HOWELL, A. B., 1920. Contribution to the life-history of the California mastiff bat. Journal of Mammalogy, I: 111-117.

KALLEN, F. C. \& GANS, C., 1972. Mastication in the little brown bat, Myotis lucifugus. Journal of Morphology, 136: 385-420.

KINGDON, J., 1974. East African Mammals. Volume II Part A (insectivores and bats). London, New York: Academic Press.

KOCK, D., 1969. Die Fledermaus Fauna des Sudan. Frankfurt am Main: Waldemar Kramer.

LUCAS, P. W., 1979. The dental-dietary adaptations of mammals. Neues Jahrbuch Geologie und Palaontologie Monatshefte, 8: 486-512.

MASTERTON, B., HEFFNER, H. \& RAVIZZA, R., 1969. The evolution of human hearing. Journal of the Acoustical Society of America, 45: 966-985.

MATTHEW, W. D., 1910. The phylogeny of the Felidae. Bulletin of the American Museum of Natural History, 28: 289-318. 
MAYNARD SMITH, J. \& SAVAGE, R. J. G., 1959. The mechanics of mammalian jaws. School Science Review, 40: 289-301.

MILLS, J. R. E., 1966. The functional occlusion of the teeth of Insectivora. Journal of the Linnean Society (Zoology), 47: $1-25$.

MILLS, J. R. E., 1967. A comparison of lateral jaw movements in some mammals from wear facets on the teeth. Archives of Oral Biology, 12: 645-661.

MOORE, W. J., 1981. The Mammalian Skull. Cambridge: Cambridge University Press.

OSBORN, H. F., 1907. Evolution of Mammalian Molar Teeth. New York: The MacMillan Company.

PINE, R. H. \& ANDERSON, J. E., 1979. Notes on the stomach contents in Trachops cirrhosus (Chiroptera: Phyllostomatidae). Mammalia, 43: 568-570.

RADINSKY, L. B., 1981a. Evolution of skull shape in carnivores. 1. Representative modern carnivores. Biological Journal of the Linnean Society, 15: 369-388.

RADINSKY, L. B., 1981b. Evolution of skull shape in carnivores. 2. Additional modern carnivores. Biological Journal of the Linnean Society, 16: 337-355.

ROBBINS, C. B., 1978. Taxonomic identification and history of Scotophilus nigrita (Schreber) (Chiroptera: Vespertilionidae). Journal of Mammalogy, 59: 212-213.

SAZIMA, I., 1978. Vertebrates as food items of the woolly false vampire, Chrotopterus auritus. Journal of Mammalogy, 59: $617-618$.

SCHALLER, G. B., 1964. The Year of the Gorilla. New York: Ballantine Books.

SICHER, H., 1944. Masticatory apparatus in the giant panda and the bears. Field Museum of Natural History (Zoological series), 29: 61-73.

SIMMONS J. A., FENTON, M. B. \& O’FARRELL, M. J., 1979. Echolocation and pursuit of prey by bats. Science, 203 : $16-21$.

SIMMONS, J. A. \& STEIN, R. A., 1980. Acoustic imaging in bat sonar: Echolocation signals and the evolution of echolocation. Journal of Comparative Physiology, 135: 61-84.

SLAUGHTER, B. H., 1970. Evolutionary trends of chiropteran dentitions. In B. H. Slaughter \& D. W. Walton (Eds). About Bats. Dallas: Southern Methodist University Press.

STANLEY, S. M., 1973. An explanation for Cope's Rule. Evolution, 27: 1-26.

STORCH, G., 1968. Funktionmorphologische Untersuchungen an der Kaumuskulatur und an Korrelierten Schadelstrukturen der Chiropteren. Abhandlungen der Senckenbergischen Naturforschenden Gesellschaft, Frankfurt am Main, 517: $1-92$.

TURNBULL, W. D., 1970. The mammalian masticatory apparatus. Field Museum of Natural History Fieldiana: Geology, 18: $149-356$.

TUTTLE, M. D. \& RYAN, M. J., 1981. Bat predation and the evolution of frog vocalizations in the Neotropics. Science, 214: 677-678 (cover).

VAUGHAN, T. A., 1976. Nocturnal behavior of the African false vampire bat (Cardioderma cor). Journal of Mammalogy, 57: $227-248$

VAUGHAN, T. A., 1977. Foraging behavior of the giant leaf-nosed bat (Hipposideros commersoni). East African Wildlife Journal, 15: 237-249.

VEHRENCAMP, S. L., STILES, F. G. \& BRADBURY, J. W., 1977. Observation on the foraging behavior and avian prey of the neotropical carnivorous bat, Vampyrum spectrum. Journal of Mammalogy, 58: 469-478.

WALKER, E. P., 1975. Mammals of the World. 3rd edition. Baltimore: The Johns Hopkins Press.

WHITAKER, J. O., JR. \& BLACK, H., 1976. Food habits of cave bats from Zambia, Africa. Journal of Mammalogy, 57: 199-204.

WHITAKER, J. O., JR. \& FINDLEY, J. S., 1980. Foods eaten by some bats from Costa Rica and Panama. Journal of Mammalogy, 61: 540-544.

YALDEN, P. W. \& MORRIS, P. A., 1975. The Lives of Bats. New York: Quadrangle/The New York Times Book Company.

\section{APPENDIX 1. SPECIES MEASURED}
A. Saccolaimus peli (Sac)
B. Taphoeous nudiventris (Tap)
C. Noctilio leporinus (Noc)
D. Nycteris grandis $(\mathrm{Nyc})$
E. Macroderma grandis (Mac)
F. Megaderma lyra (Meg)
G. Cardioderma cor (Car)
H. Rhinolophus bctus (Rlu)
I. Rhinolophus rufus (Rru)
J. Hipposideros commersoni gigas (Hcg)
K. Hipposideros c. commersoni (Hcc)
L. Hipposideros lankadiva (Hla)
M. Hipposideros pratti (Hpr)

N. Vampyrum spectrum (Vam)

O. Phyllostomus hastatus (Phy)

P. Chrotopterus auritus (Chr)

Q. Trachops cirrhosus (Tra)

R. Scotophilus gigas (Sco)

S. Ia io (Ia)

T. Myotis myotis (Myo)

U. Nyctalus lasiopterus (Nla)

V. Cheiromeles torquatus (Chi)

W. Eumops perotis (Epr)

X. Eumops underwoodi (Eun)

Y. Otomops martiensseni (Oto) 


\author{
Small bats: \\ Z. Peropteyx kappleri (Per) \\ 1. Rhinolophus blasii (Rbl) \\ 2. Hipposideros caffer (Hcf) \\ 3. Macrotus californicus (Mca)
}

\author{
4. Lasiurus borealis (Las) \\ 5. Myotis velifer (Mvl) \\ 6. Tadarida brasiliensis (Tad) \\ 7. Molossus molossus (Mol)
}

\section{APPENDIX 2. CHARACTERS}

1. Condylocanine length (CCL) - from occipital condyle to anterior edge of canine.

2. Maxillary toothrow (MTR) - length from posterior edge of M3 to anterior edge of canine (not alveolar length).

3. Zygomatic breadth — greatest width across the zygoma.

4. Maxillary breadth — greatest width across maxilla from the labial sides of the M3s. Divided by maxillary toothrow for relative width.

5. Upper canine length — greatest length from dorsal rim of cingulum to ventral tip of unworn tooth.

6. Dentary length (DL) - from midpoint of mandibular condyle to anterior edge of dentary.

7. Dentary thickness - a calculation taken from the area of the depth and lateral width of the dentary at the base of the protoconid of $\mathrm{M}_{2}$. Following Radinsky, 1981a, the second moment of the area is derived and converted to the fourth root for comparison with other linear measurements.

8. Coronoid height - greatest length from tip of coronoid to indentation in the ventral border of dentary.

9. Height of condyle - the height in lateral view from a line (cross hair in microscope) through the valleys between the protoconids and hypoconids of M, and M3 to the superior edge of the mandibular condyle.

10. Temporal volume - (a) temporal fossa length-greatest length from the posteriormost edge of either the lambdoidal or sagittal crest to the anteriormost muscle scars at the eminence posterior to the eye. This point is homologous to a postorbital process and the scars can usually be located under a scope with good light. Used in calculation of temporal volume. (b) Temporal fossa depth-derived by subtracting the width at the postorbital constriction from the zygomatic breadth and dividing by 2 . Used in calculation of temporal volume. (c) Temporal fossa height-from the glenoid cavity to a point on the sagittal crest directly dorsal to the cavity. Usually the lower jaw of the calipers will rest in both cavities and against the postglenoid processes. Used in calculation of temporal volume.

11. Midpoint of temporal - an angle taken from drawing of lateral side of skull between a line drawn through the midpoint of the temporal fossa length and tip of the coronoid and a line through the glenoid cavity and the anterior junction of M' with the maxilla. The angle indicates the degree of vertical orientation of the temporal fossa relative to the coronoid process.

12. Temporal origin/temporal insertion - a ratio of the origin, from the condyle to the midpoint of the temporal fossa length (see Emerson \& Radinsky, 1980), over the length of the insertion, from the condyle to the tip of the coronoid. These are taken from the drawing of the lateral side of the skull and used in estimating the gape of the temporal muscle.

13. Temporal $\varphi$-the angle between the insertion and origin taken from lateral drawing and presumably related to gape (Emerson and Radinsky, 1980).

14. Masseter volume - (a) masseter length - also the masseter origin, from the glenoid fossa to the anteriormost extent of muscle scar on the ventral surface of the anterior junction of the zygoma with the maxilla (scars can be seen with scope). Used in formulation of masseter volume and masseter origin/insertion ratio (Herring \& Herring, 1974) in estimating gape of masseter. (b) Masseter depth - a figure derived from subtracting the width between the lingual mandibular foramen at the base of the coronoids from the zygomatic breadth and dividing by 2. Disarticulated mandibles can be easily reglued at the symphysis by keeping the cranium upside down during the glueing process and allowing the mandible to rest properly in the upper toothrows. Used in calculation of masseter volume. (c) Masseter width - also the masseter insertion, from the midpoint of the condyle to the tip of the angular process. Used in the calculation of the masseter volume and for masseter insertion/origin ratio in connection with estimating gape (Herring \& Herring, 1974).

15. Masseter origin/masseter insertion - a ratio of the masseter length over masseter width.

16. Masseter $\varphi$ - the angle between the origin and insertion taken from a lateral drawing and used in estimating gape (Herring \& Herring, 1974).

17. Relative molar area - the area of the occlusal surface of the upper $\mathrm{P}^{4}-\mathrm{M}^{3}$ taken with a polar planimeter from a drawing. Converted to its square root for comparison with linear measurements. Relative area derived by dividing by upper molar row length taken from drawing (anterior edge of $\mathrm{P}^{4}$ to posterior edge of $\mathrm{M}^{3}$ ).

18. Relative stylar shelf area - occlusal area of upper $\mathrm{P}^{4}-\mathrm{M}^{3}$ of the stylar shelf only, the raised shelf limited by the ectoloph on the lingual side, including the paracone and parastyle of $\mathrm{P} 4$ and converted to square root for linear comparison. Relative stylar area derived by dividing by upper molar row length $\left(\mathrm{P}^{4}-\mathrm{M}^{3}\right)$ taken from drawing.

19. Total intraloph/interloph - a ratio of the sum of the lengths of the internal cusps on the upper molar (postparacrista and premetacrista) over the sum of the lengths of shared cusps between the molars (the metacrista of the anterior molar or parastyle of $\mathrm{P}^{4}$ and the paracrista of the following molar). There are three of these sets of cusps that can be measured in the upper toothrow, when summed they make the total intraloph/interloph $\left(\mathrm{P}^{4}-\mathrm{M}^{3}\right)$ ratio. 
20. $\mathrm{M}_{3}$ talonid/ $\mathrm{M}_{3}$ trigonid - a ratio representing the relative occlusal width of the talonid to the trigonid of $M$,. The talonid becomes smaller as the premetacrista of the $\mathrm{M}^{3}$ decreases in size and the ratio is $<1.0$. A ratio of $<1.0$ represents equal talonid and trigonid.

21. $\mathrm{M}_{2}$ hypoconid/ $\mathrm{M}_{2}$ protoconid - a ratio representing the relative lateral height of the hypoconid to the protoconid. A ratio of 1.0 means equal cusp heights, and $<1.0$ when the hypoconid is smaller than the protoconid.

22. Braincase volume - volume of braincase is derived from the amount of lead dust shot (\# 12) contained in the braincase and converted to the cube root for linear comparison.

23. Basicranial angle - taken from lateral drawing of the cranium from the basicranial axis (where a pin has been glued to the basicranium) to a line passing through the juncture of the maxilla and anterior edge of the canine and posterior edge of $\mathrm{M}^{3}$.

24. Ear area - greatest length times greatest width of pinna of wet specimen and converted to square root for linear comparison.

\section{APPENDIX 3.}

Ten characters (logged to base 10) correlated with SIZE. Abbreviations are found in Appendix 1.

A. Condylocanine length. B. Zygomatic breadth. C. Maxillary toothrow length. D. Upper canine length. E. Dentary thickness. F. Dentary length. G. Masseter volume. H. Temporal volume. I. Brain volume. J. Coronoid height. The carnivorous bats are denoted by squares.
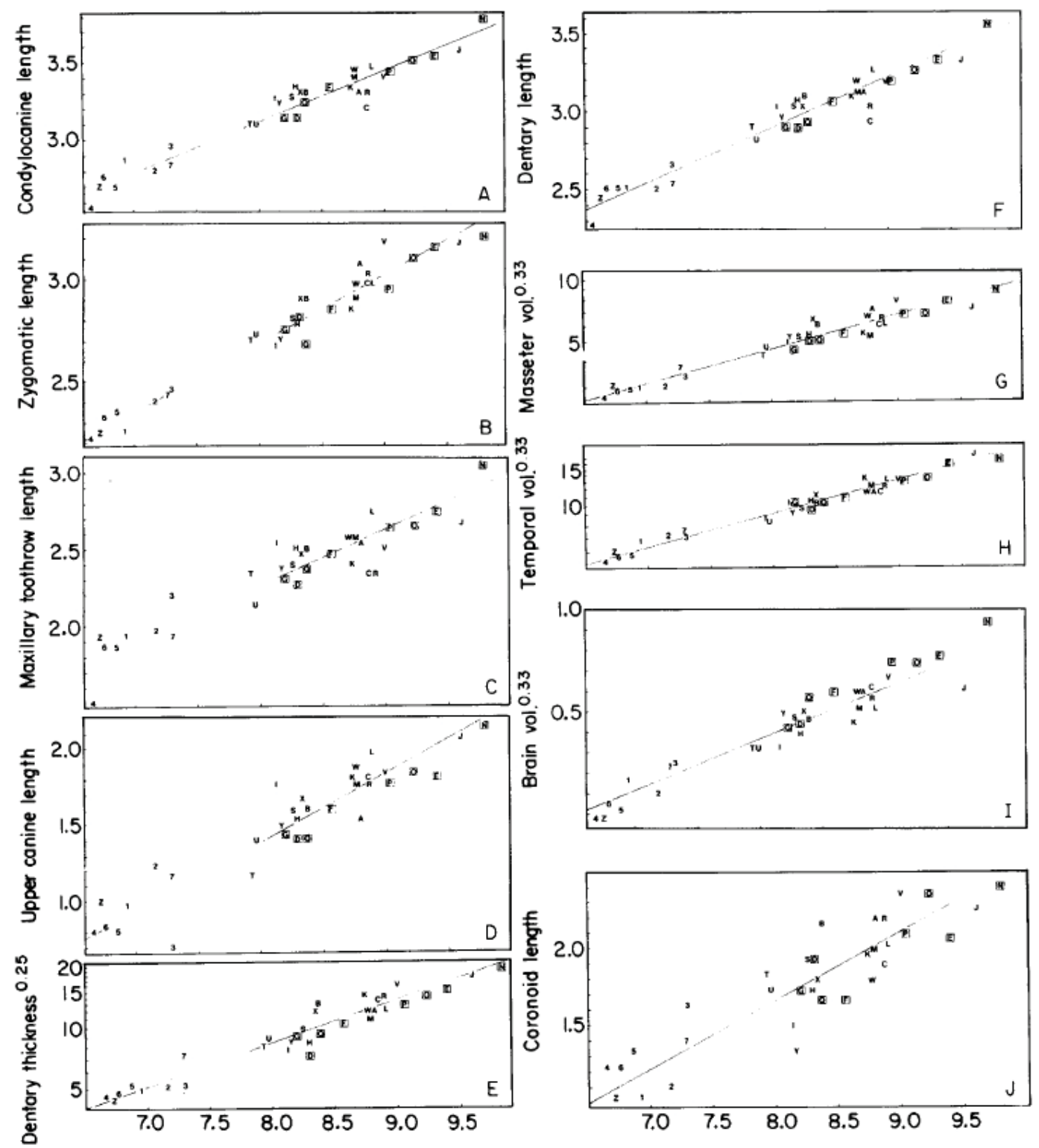


\section{APPENDIX 4.}

Reduced major axes of logged (base 10) data ${ }^{\dagger}$

\begin{tabular}{|c|c|c|c|c|c|}
\hline Character & Mean & SD & Slope & Intercept & Correlation \\
\hline v. SIZE & 8.254 & 0.866 & & & $>0.34 *$ \\
\hline Condylocanine length & 3.198 & 0.285 & 0.329 & 0.482 & $0.967^{*}$ \\
\hline Maxillary toothrow & 2.348 & 0.313 & 0.361 & -0.635 & $0.923^{*}$ \\
\hline Zygomatic breadth & 2.771 & 0.293 & 0.338 & -0.022 & $0.978^{*}$ \\
\hline Maxillary breadth & 2.357 & 0.258 & 0.298 & -0.102 & $0.875^{*}$ \\
\hline Upper canine length & 1.497 & 0.386 & 0.446 & -2.182 & $0.934^{*}$ \\
\hline Dentary length & 2.952 & 0.307 & 0.354 & 0.030 & $0.967^{*}$ \\
\hline Dentary thickness & -0.030 & 0.180 & 0.208 & 1.746 & $0.960^{*}$ \\
\hline Coronoid height & 1.782 & 0.395 & 0.456 & -1.980 & $0.900^{*}$ \\
\hline Height of condyle & -0.063 & 1.023 & -1.181 & 9.685 & -0.186 \\
\hline Temporal volume & 1.000 & 0.140 & 0.162 & -0.334 & $0.990^{*}$ \\
\hline Midpoint of temporal & $36.67^{\circ}$ & 11.847 & 13.680 & -76.246 & 0.159 \\
\hline Temporal origin/insertion & 0.593 & 0.177 & 0.204 & -1.094 & -0.235 \\
\hline Temporal $\phi$ & $67.24^{\circ}$ & 13.026 & 15.042 & -56.913 & -0.327 \\
\hline Masseter volume & 0.700 & 0.140 & 0.162 & -0.634 & $0.970^{*}$ \\
\hline Masseter origin/insertion & 0.630 & 0.140 & 0.162 & -0.704 & 0.051 \\
\hline Masseter $\phi$ & $78.45^{\circ}$ & 7.344 & 8.480 & 8.453 & 0.033 \\
\hline Molar area & 0.590 & 0.120 & 0.138 & -0.554 & $0.950^{*}$ \\
\hline Stylar shelf area & 0.450 & 0.130 & 0.150 & -0.789 & $0.970^{*}$ \\
\hline Braincase volume & 0.443 & 0.240 & 0.277 & -1.844 & $0.961^{*}$ \\
\hline Basicranial angle & $98.21^{\circ}$ & 14.020 & 16.189 & -35.417 & -0.113 \\
\hline Zygomatic br./CCL & $65.57 \%$ & 6.880 & 7.945 & -0.008 & 0.110 \\
\hline Upper canine/MTR & $43.35 \%$ & 7.540 & 8.707 & -28.520 & $0.380^{*}$ \\
\hline Dentary thickness/DL & $4.98 \%$ & 0.930 & 1.074 & -3.88 & $0.580^{*}$ \\
\hline Temporal volume/DL & $52.39 \%$ & 0.482 & 5.566 & 6.450 & 0.180 \\
\hline Masseter volume/DL & $26.32 \%$ & 0.252 & 2.291 & 2.300 & 0.210 \\
\hline Rel. molar area & $48.59 \%$ & 8.170 & 9.434 & -29.280 & 0.150 \\
\hline $\begin{array}{l}\text { Rel. stylar shelf area } \\
\text { v. Basicranial angle }\end{array}$ & $36.17 \%$ & 2.180 & 2.517 & 15.392 & 0.040 \\
\hline Height of condyle & -0.063 & 1.023 & 0.073 & -7.229 & $0.595^{*}$ \\
\hline Midpoint of temporal & $36.67^{\circ}$ & 11.847 & -0.845 & 119.654 & $-0.750^{*}$ \\
\hline Ear area & 1.350 & 0.160 & 0.011 & 0.277 & $-0.430^{*}$ \\
\hline
\end{tabular}

$\dagger$ Angles and ratios are not logged; areas and volumes have been taken to the appropriate root. $N$ is 33 except for Ear area (29) 